\title{
Benign Intraocular Teratoid Medulloepithelioma
}

National Cancer Institute

\section{Source}

National Cancer Institute. Benign Intraocular Teratoid Medulloepithelioma. NCI

Thesaurus. Code C66809.

A rare, unilateral, benign embryonic neoplasm typically presenting as a cilliary body mass during childhood. It is composed of medullary epithelial cells and heterologus elements, particularly cartilage, skeletal muscle, and brain tissue. 